\title{
Acid-base indicators in the venous and arterial blood of horses affected by recurrent airway obstruction (RAO)
}

\author{
A. Stopyra, P. Sobiech, A. Wacławska-Matyjasik \\ Department and Clinic of Internal Diseases, Faculty of Veterinary Medicine, \\ University of Warmia and Mazury, Oczapowskiego 14, 10-719 Olsztyn, Poland
}

\begin{abstract}
The acid-base equilibrium is closely linked to gas exchange in the lungs, and respiratory exchange ratios are used to evaluate respiratory effectiveness and tissue oxygen levels. Acid-base indicators are determined in both arterial and venous blood samples. This study compares the usefulness of acid-base indicators of venous and arterial blood in monitoring the condition of horses with recurrent airway obstruction. Prior to treatment involving bronchodilating glucocorticoids, expectorant and mucolytic drugs, more pronounced changes were observed in venous blood $\left(\mathrm{pH} 7.283, \mathrm{pCO}_{2} 61.92\right.$ $\mathrm{mmHg}, \mathrm{pO}_{2} 35.541 \mathrm{mmHg}, \mathrm{HCO}_{3}{ }^{-} 31.933 \mathrm{mmHg}, \mathrm{BE} 2.933 \mathrm{mmol} / \mathrm{l}, \mathrm{O}_{2} \mathrm{SAT} 58.366 \%, \mathrm{ctCO}_{2} 38.333$ $\mathrm{mmol} / \mathrm{l})$ than in arterial blood $\left(\mathrm{pH} 7.309, \mathrm{pCO}_{2} 53.478 \mathrm{mmHg}, \mathrm{pO}_{2} 90.856 \mathrm{mmHg}, \mathrm{HCO}_{3}^{-} 28.50\right.$ $\mathrm{mmHg}, \mathrm{BE} 3.133 \mathrm{mmol} / \mathrm{l}, \mathrm{O}_{2} \mathrm{SAT} 93.375 \%$, $\left.\mathrm{ctCO}_{2} 31.652 \mathrm{mmol} / \mathrm{l}\right)$, indicating compensated respiratory acidosis. The improvement of respiratory efficiency minimized acidosis symptoms in both venous blood (pH 7.365, $\mathrm{pCO}_{2} 43.55 \mathrm{mmHg}, \mathrm{pO}_{2} 47.80 \mathrm{mmHg}, \mathrm{HCO}_{3}^{-} 30.325 \mathrm{mmHg}, \mathrm{BE} 3.050 \mathrm{mmol} / \mathrm{l}$, $\left.\mathrm{O}_{2} \mathrm{SAT} 80.10 \%, \mathrm{ctCO}_{2} 29.80 \mathrm{mmol} / \mathrm{l}\right)$ and arterial blood $\left(\mathrm{pH} 7.375, \mathrm{pCO}_{2} 39.268 \mathrm{mmHg}, \mathrm{pO}_{2} 98.476\right.$ $\mathrm{mmHg}, \mathrm{HCO}_{3}{ }^{-} 26.651 \mathrm{mmHg}, \mathrm{BE} 4.956 \mathrm{mmol} / \mathrm{l}, \mathrm{O}_{2} \mathrm{SAT} 98.475 \%$, ctCO $\left.28.131 \mathrm{mmol} / \mathrm{l}\right)$. Venous blood parameters were marked by greater deviations from mean values, both before and after treatment. Acid-base indicators determined in venous blood are indicative of respiratory disturbances, but they do not support a comprehensive evaluation of gas exchange in the lungs.
\end{abstract}

Key words: acid base balance, blood, recurrent airway obstruction, horses

\section{Introduction}

The acid-base equilibrium is an indicator of metabolic changes in the body. An acid-base imbalance could be the underlying cause of pathological states, but it is more likely to accompany other bodily dysfunctions, contributing to various complications, and obstructing a correct diagnosis and therapy.

Acid-base indicators should be determined in arterialized capillary blood and, preferably, in whole arterial blood which is a more robust indicator of blood oxygen levels and alveolar gas exchange (Sobiech et al. 2005). Blood gasometry and acid-base analyses are generally performed in horses with acute health problems or during surgical procedures, and arterial blood is sampled under clinical conditions. Recent research findings indicate the significance of acid-base indicators in equine drug tests, increasing the demand for blood analysis in field conditions (Ferro et al. 2002). In the past two decades, solutions 
of sodium bicarbonate, glucose and vitamins (milkshakes) have been increasingly often administered to racehorses by stomach tube. The use of milkshakes directly before racing produces a metabolic acidosis, neutralizes acidic metabolites which are formed during muscular activity, and increases the horse's overall performance. The only method for detecting the presence of bicarbonates is an analysis of total carbon dioxide concentrations $\left(\mathrm{ctCO}_{2}\right)$ (McKeever 2005). Elevated blood $\mathrm{CO}_{2}$ levels indicate the use of sodium bicarbonate (Auer et al. 1993).

Impaired gas exchange in the lungs is also manifested by changes in acid-base indicators. In recurrent airway obstruction, the amount of air in the lower respiratory tract is decreased as the result of an allergic reaction, and alveolar gas exchange is suppressed. Exposure to allergens in airborne dust in stables and pastures leads to the accumulation of inflammatory mediators and the infiltration of lymphocytes, mast cells and plasma cells in the bronchial walls. Inflammatory mediators cause the smooth muscles of the bronchi to contract and undergo hypertrophy. Chronic inflammations lead to the hypertrophy of goblet cells and excessive accumulation of mucus whose viscosity increases due to glycosylation. These reactions are intensified during exposure to allergens, inducing permanent changes in the structure and function of the lower airway (Niedźwiedź et al. 2006). According to Chevalier and Divers (2003), the monitoring of gasometric and acid-base indicators is one of the best methods of evaluating blood - air gases exchange efficiency in the lungs.

The collection of arterial blood samples from horses under field conditions, independently from the facial, jaw or common carotid artery, requires skill and experience, it could produce more serious complications than venous blood sampling and the arterial puncture, in the animals' owners' opinion, is more dangerous for horses. The collection of arterialized capillary blood samples from the ear lobe or the finger, a standard method applied in other animal species, is not widely used in horses (Chevalier and Divers 2003).

\section{Objective}

The objective of this study was to compare the usefulness of acid-base indicators of arterial and venous blood in diagnosing respiratory exchange problems in horses with recurrent airway obstruction.

\section{Materials and Methods}

The experimental materials comprised 18 horses of various breeds and performance categories, aged
4 to 12 years. They were chosen from a group of 62 animals with different stages of recurrent airway obstruction (RAO). Before the start of this investigation they were clinically (body heat, pulse, number and character of breaths, mucosal membranes state etc.) and laboratory (hematology parameters, serum concentration of $\mathrm{Na}^{+}, \mathrm{K}^{+}, \mathrm{Cl}^{-}$) tested and showed no disease symptoms except RAO. All 18 animals were diagnosed with RAO at a similar stage. Exercise intolerance, a chronic spontaneous cough, an accentuated expiratory effort and tachypnea were present in all horses and 16 of them had a mucopuruental nasal discharge. Ausculation revealed respiratory wheezes and crackles. All animals were endoscopically examined with bronchoalveoral lavage (BAL). This revealed excessive mucous exudates within the trachea. BAL revealed an increase of neutrofil percentage above $58 \%$.

Blood samples were collected before diagnosis and after treatment.

The therapy involved a change of housing conditions to minimize exposure to airborne allergens and irritants. Dexamethasone was administered intravenously to treat inflammations $(0.04-0.05 \mathrm{mg} / \mathrm{kg}$ BW/day) once every two days, for two weeks. Ipratropium bromide inhalation solution (90-180 g/horse) was used to relax the bronchial muscle and dilate the bronchial lumen. Bronchial mucus was dissolved and evacuated by acetylcysteine inhalation (1.5-2.5 g/animal) and intramuscular administration of bromhexine $(35-40 \mathrm{mg} /$ horse). The inhalations were made twice per day. The horses were lunged two times a day for 20 minutes ( 5 minutes of walk, 10 of trot and 5 of walk again) after inhalation to clear the airway, and then were allowed in the field for 1-2 hours. Therapy was ended 3-5 days after the symptoms subsided and gasometry, acid-base balance parameters and BAL were not abnormal. This took about four weeks.

Blood was sampled from the external jugular vein and the common carotid artery before the first morning feed, directly from the $20 \mathrm{G}$ injection needle $(0.9 / 40)$ to glass capillary tubes containing heparin, with a metal wire for sample mixing. Acid-base indicators were determined in a Rapidlab 348 analyzer within 5 minutes after sampling based on measurements of rectal temperature. The following blood parameters were determined: $\mathrm{pH}$, partial pressure of carbon dioxide $\left(\mathrm{pCO}_{2}\right)$, partial pressure of oxygen $\left(\mathrm{pO}_{2}\right)$, bicarbonate ion concentrations $\left(\mathrm{HCO}_{3}^{-}\right)$, base excess (BE), oxygen saturation $\left(\mathrm{O}_{2} \mathrm{SAT}\right)$ and total carbon dioxide concentrations $\left(\mathrm{ctCO}_{2}\right)$. The results, processed statistically using Student's t-test, are presented in Table 1. 
Table 1. Acid-base indicators of venous and arterial blood samples collected from horses with RAO before and after treatment.

\begin{tabular}{|c|c|c|c|c|c|c|c|c|}
\hline & & $\mathrm{pH}$ & $\mathrm{pCO}_{2}$ & $\mathrm{PO}_{2}$ & $\mathrm{HCO}_{3}^{-}$ & $\mathrm{BE}$ & $\mathrm{O}_{2} \mathrm{SAT}$ & $\operatorname{ctCO}_{2}$ \\
\hline & & & $\mathrm{mmHg}$ & $\mathrm{mmHg}$ & $\mathrm{mmol} / \mathrm{l}$ & $\mathrm{mmol} / \mathrm{l}$ & $\%$ & $\mathrm{mmol} / \mathrm{l}$ \\
\hline \multirow{4}{*}{ Venous blood } & I & 7.283 & $61.92^{\mathrm{b}}$ & $35.541^{\mathrm{ab}}$ & 31.933 & 2.933 & $58.366^{\mathrm{ab}}$ & $38.333^{\mathrm{ab}}$ \\
\hline & $\bar{x}$ & 0.052 & 8.464 & 11.231 & 10.746 & 2.274 & 14.797 & 5.750 \\
\hline & II & 7.365 & $43.55^{\mathrm{b}}$ & $47.8^{\mathrm{ab}}$ & 30.325 & 3.050 & $80.1^{\mathrm{ab}}$ & $29.8^{\mathrm{b}}$ \\
\hline & $\bar{x}$ & 0.065 & 4.889 & 8.788 & 9.038 & 2.071 & 9.364 & 10.041 \\
\hline \multirow{4}{*}{ Arterial blood } & I & 7.309 & 53.478 & $90.856^{\mathrm{a}}$ & 28.250 & $3.133^{\mathrm{b}}$ & $93.375^{\mathrm{a}}$ & $31.652^{\mathrm{a}}$ \\
\hline & $\bar{x}$ & 0.051 & 5.662 & 2.757 & 5.357 & 2.243 & 10.251 & 4.813 \\
\hline & II & 7.375 & 39.268 & $98.476 \mathrm{a}$ & 26.651 & $4.956 \mathrm{~b}$ & $98.475 \mathrm{a}$ & 28.131 \\
\hline & 0.052 & 3.412 & 1.626 & 4.992 & 1.028 & 8.452 & 5.237 & \\
\hline
\end{tabular}

a - significant at $\mathrm{p} \leq 0.05$ (venous/arterial blood)

b - significant at $\mathrm{p} \leq 0.05$ (first/second sampling)

I - sampled before diagnosis

II - sampled after treatment

\section{Results}

The values of acid-base indicators of arterial and venous blood sampled from horses with recurrent airway obstruction (RAO) before treatment revealed compensated respiratory acidosis (Table 1). More pronounced changes were observed in venous blood than in arterial blood samples. The $\mathrm{pH}$ of venous blood (mean 7.238) was insignificantly lower than that of arterial blood ( mean 7.309). The mean value of base excess $(\mathrm{BE})$ was determined at $2.933 \mathrm{mmol} / \mathrm{l}$ in venous blood and $3.133 \mathrm{mmol} / \mathrm{l}$ in arterial blood. Bicarbonate ion concentrations $\left(\mathrm{HCO}^{33-}\right)$ and the partial pressure of carbon dioxide $\left(\mathrm{pCO}_{2}\right)$ were higher in venous blood (mean $31.933 \mathrm{mmol} / \mathrm{l}$ and $61.92 \mathrm{mmol} / \mathrm{l}$, respectively) than in arterial blood samples (mean $28.25 \mathrm{mmol} / \mathrm{l}$ and $53.478 \mathrm{mmol} / \mathrm{l}$, respectively). Significant differences between venous and arterial blood samples were reported as regards the partial pressure of oxygen $\left(\mathrm{pO}_{2}\right)$ (mean 35.541 and $90.856 \mathrm{mmHg}$, respectively) and oxygen saturation $\left(\mathrm{O}_{2} \mathrm{SAT}\right)$ (mean 58.366 and $93.375 \%$, respectively). Total carbon dioxide concentrations $\left(\mathrm{ctCO}_{2}\right)$ were lower in arterial blood (mean $31.652 \mathrm{mmol} / \mathrm{l}$ ) than in venous blood (mean $38.333 \mathrm{mmol} / \mathrm{l}$ ).

After the improvement of respiratory efficiency the parameters of the acid-base equilibrium changed (Table 1). The mean $\mathrm{pH}$ values of venous and arterial blood increased to reach 7.375 in arterial blood and 7.365 in venous blood. The remaining parameters were characterized by similar differences. In venous blood samples, the partial pressure of carbon dioxide (mean $43.55 \mathrm{mmHg}$ ), total carbon dioxide concentrations (mean $29.8 \mathrm{mmol} / \mathrm{l}$ ) and bicarbonate concentrations (mean $30.325 \mathrm{mmol} / \mathrm{l}$ ) were determined at a higher level than in arterial blood (mean
$39.268 \mathrm{mmHg}, 28.131 \mathrm{mmol} / \mathrm{l}$ and $26.651 \mathrm{mmol} / \mathrm{l}$, respectively). In arterial blood samples, base excess (mean $4.956 \mathrm{mmol} / \mathrm{l}$ ), the partial pressure of oxygen (mean $98.476 \mathrm{mmHg}$ ) and oxygen saturation (mean $98.475 \%$ ) values were significantly higher than in venous blood (mean $3.05 \mathrm{mmol} / \mathrm{l}, 47.80 \mathrm{mmHg}$ and $80.10 \%$, respectively).

A comparison of test results acquired before and after treatment revealed significant differences in acid-base indicators, in particular in venous blood samples. The partial pressure of carbon dioxide decreased significantly from mean 61.92 to $43.55 \mathrm{mmHg}$ in venous blood and from mean 53.478 to 39.268 $\mathrm{mmHg}$ in arterial blood. An equally pronounced drop was noted in total carbon dioxide concentrations, from mean 38.333 to $29.8 \mathrm{mmol} / \mathrm{l}$ in venous blood and from mean 31.652 to $28.131 \mathrm{mmol} / \mathrm{l}$ in arterial blood. The partial pressure of oxygen increased from mean 35.541 to $47.80 \mathrm{mmHg}$ in venous blood and from mean 90.856 to $98.476 \mathrm{mmHg}$ in arterial blood, and oxygen saturation levels rose from mean 58.366 to $80.10 \%$ and from mean 93.375 to $98.475 \%$, respectively. A notable increase in base excess parameters was reported in arterial blood, from mean 3.133 to 4.956 $\mathrm{mmol} / \mathrm{l}$. The results of venous blood analyses performed before and after treatment were characterized by greater deviations from mean values than the respective parameters of arterial blood samples (Table 1).

\section{Discussion}

Chronic respiratory failure is increasingly often recognized as the cause of deteriorating physical performance in horses. Respiratory failure lowers exer- 
cise tolerance, but it rarely produces distinctive clinical symptoms. Therefore, a correct diagnosis requires specific procedures, such as determinations of acid-base indicators and arterial blood gas tests. These parameters support an evaluation of gas exchange in the alveoli of the lungs. Bronchoalveolar lavage (BAL) is yet another useful procedure which assesses the condition of the respiratory epithelium based on the number and type of cells present in the airway, is better than gasometry or acid-base balance parameters for diagnosis, but does not support an evaluation of respiratory gas exchange effectiveness (Ferro et al. 2002).

Horses with RAO show symptoms of respiratory failure and impaired alveolar gas exchange due to a constricted bronchial lumen and mucus accumulation (Niedźwiedź et al., 2006). The above result in hypoxia, manifested by decreased partial pressure of oxygen, lower oxygen saturation levels, increased partial pressure of carbon dioxide and a drop in blood $\mathrm{pH}$, observed in examined horses (Table 1). Similar RAO symptoms have been described by Ryhner et al. (2008). According to Johnson (1995), hypoxia accompanies persistent lung inflammations or obstructive lung diseases in horses, such as recurrent airway obstruction. Respiratory acidosis induces compensatory mechanisms that increase bicarbonate concentrations and total carbon dioxide levels in horses affected by RAO. More pronounced changes are observed in venous blood, compared with arterial blood (Table 1). The acid-base equilibrium of venous blood is determined by the intensity and type (aerobic/anaerobic) of cell metabolism, the release of hydrogen ions and the production of $\mathrm{CO}_{2}$ transported to the lungs (Aguillera-Tejero et al. 1998). Venous blood samples were characterized by higher concentrations of metabolic components $\left(\mathrm{HCO}_{3}{ }^{-}\right.$and $\left.\mathrm{ctCO}_{2}\right)$. The partial pressure of carbon dioxide in arterial blood is affected by the effectiveness of alveolar gas exchange (Bergeroa et al. 2005). According to Piccone et al. (2004), differences in oxygen saturation and partial oxygen pressure in venous and arterial blood can be attributed to variations in oxygen supply to tissues, and to higher acidity and higher temperature in the capillaries which lead to oxyhemoglobin dissociation and is manifested by lower oxygen pressure and decreased oxygen saturation levels in venous blood (Table 1). Arterial blood flowing from the lungs is characterized by lower temperature, a lower content of carbonic acid anhydride and higher $\mathrm{pH}$ which contributes to higher oxygen saturation and increased oxygen pressure in comparison with venous blood (Table 1). Gauvreau et al. (1996) reported no significant changes in oxygen pressure and saturation in venous blood samples collected from horses after exercise and explained this as the predominance of anaerobic metabolism in myocytes, accompanied by simultaneous hyperventilation. The results of our previous work (Stopyra 2002) suggest that the acid-base parameters of venous blood are a more robust indicator of metabolic changes which in horses take place predominantly in muscles. According to Piccone et al. (2004), oxygen pressure and saturation levels in arterial blood are indicative of the efficiency of alveolar gas exchange.

The treatment of horses affected by RAO with the use of anti-inflammatory, mucolytic, expectorant and bronchodilating drugs, physiotherapy and improvement of housing conditions normalized acid-base indicators. The applied therapy produced more pronounced differences in venous blood, including a drop in carbon dioxide pressure, total carbon dioxide concentrations, an increase in oxygen pressure and oxygen saturation levels, which, according to Gollnicka et al. (1990), could suggest lower demand for oxygen in tissues. Similar, but less notable variations were found in arterial blood, including higher $\mathrm{pH}$ and a significant increase in base excess values due to lower bicarbonate concentrations. As noted by Orson and Fuster (2003) as well as Cambier et al. (2005), oxygen saturation levels are not determined by oxygen pressure alone, but also by local pH, 2,3-DPG concentrations, temperature and oxyhemoglobin concentrations. Oxygen saturation $\left(\mathrm{O}_{2} \mathrm{SAT}\right)$ is indicative of the amount of oxygen that is bound to hemoglobin in the blood. Similarly to oxygen levels, oxygen saturation levels in the analyzed horses were also higher in arterial blood samples (Table 1).

The described changes indicate that the applied therapy improved alveolar gas exchange and increased the supply of oxygen. Venous blood parameters indicate reduced tissue hypoxia and hypercapnia, but due to the variety of factors that affect tissue metabolism, the obtained results do not support a conclusive evaluation of respiratory effectiveness. The results of arterial blood tests are more stable, and the noted acid-base indicators are characterized by lower standard deviations. According to Chevalier and Divers (2003) and Divers (2003), arterial blood gasometry parameters are the most robust indicators of gas exchange, in particular in evaluations of the effectiveness of oxygen treatment in critical patients. Venous blood parameters may also be used to assess changes in acid-base indicators.

The present study indicates that arterial blood samples produce more reliable blood gas and acid-base parameters for assessing respiratory effectiveness. Gasometry parameters and acid-base indicators of venous blood can be used in indirect evaluations of the blood-air barrier as a measure of tissue response to changes in gas exchange in the lungs. 


\section{References}

Aguilera-Tejero E, Estepa JC, Lopez I, Bas S, Mayer-Valor R, Rodriguez M (2000) Quantitative analysis of acid-base balance in show jumpers before and after exercise. Res Vet Sci 68: 103-108.

Auer DE, Skelton KV, Tay S, Baldock FC (1993) Detection of bicarbonate administration (milkshake) in standardbred horses. Aust Vet J 70: 336-340.

Bergero D, Assenza A, Caola G (2005) Contribution to our knowledge of the physiology and metabolism of endurance horses. Livest Prod Sci 92: 167-176.

Cambier C, Di Passio N, Clerbaux T, Amory H, Marville V, Detry B, Frans A, Gustin P (2005) Blood-oxygen binding in healthy Standardbred horses. Vet J 169: 251-256.

Chevalier H, Divers TJ (2003) Pulmonary Dysfunction in Adult Horses in the Intensive Care. Unit Clinl Tech Eq Pract 2: 165-177.

Divers TJ (2003) Monitoring Tissue Oxygenation in the ICU Patient. Clinl Tech Eq Pract 2: 138-144.

Ferro E, Ferrucci F, Zucca E, Di Fabio V, Castoldi S (2002) Arterial blood gas analysis in 53 racehorses with a diagnosis of small airway inflamatory disease (SAID). J Eq Vet Sci 22: 165-168.

Gauvreau GM, Young SS, Staempfli H, McCutcheon LJ, Wilson BA, McDonnell WN (1996) The relationship between respiratory exchange ratio, plasma lactate and muscle lactate concentrations in exercising horses using a valved gas collection system. Can J Vet Res 60: 161-171.
Johnson PJ (1995) Electrolyte and acid-base disturbances in the horse. Vet Clin North Am Equine Pract 11: 491-514.

McKeever KH (2005) Can feed cause a positive blood test in racehorses? Some recent information on the effect of dietary supplements on plasma $\mathrm{tCO}_{2}$ cocncentration in horses. Adv Eq Nutr 3: 69-76.

Moe OW, Fuster D (2003) Clinical acid-base pathophysiology: disorders of plasma anion gap. Best Pract Res Clin Endocrinol Metab 17: 559-574.

Niedźwiedź A, Nicpoń J, Różycki P (2006) Pathogenesis, diagnosis and treatment of Recurrent Equine Airway Obstruction. Med Weter 62: 512-515.

Piccione G, Ferrantelli V, Fazio F, Percipalle M, Caola $G$ (2004) Blood-gas profile in the show jumper undergoing increasing workloads during a 2-day event. Comp Clin Pathol 13: 43-50.

Ryhner T, Muller N, Balmer V, Gerber V (2008) Increased mucus accumulation in horses chronically affected with recurrent airway obstruction is not associated with up-regulation of CLCA1, EGFR, MUC5AC, Bcl-2, IL-13 and INF-gamma expression. Vet Immunol Immunopathol 125: 8-17.

Sobiech P, Stopyra A, Kuleta Z, Zbanyszek M, Milewski $S$ (2005) Acid-base balance parameters of arterial, venous and capillary blood in sheep. Bull Vet Inst Pulawy 49: $125-127$.

Stopyra A (2002) Gasometry indices and the activity of selected enzymes in horse serum during extreme exertion. Med Weter 58: 543-548. 